\title{
MENINAS BEM-COMPORTADAS, BOAS ALUNAS; MENINOS INTELIGENTES, INDISCIPLINADOS
}

\author{
CÁRMEN A. DUARTE DA SILVA \\ Faculdade de Educação da Universidade Federal de Pelotas \\ FERNANDO BARROS e SÍLVIA C. HALPERN \\ Faculdade de Medicina da Universidade Federal de Pelotas \\ LUCIANA A. DUARTE DA SILVA \\ Bolsista da Fapergs \\ RESUMO
}

Estudo longitudinal vem acompanhando todas as crianças nascidas em Pelotas, Rio Grande do Sul, no ano de 1982. Suas trajetórias escolares mostraram-se fortemente determinadas pela variável gênero, mesmo quando eliminados por estatística outros fatores intervenientes. Um estudo com 84 professoras/ es buscou identificar que processos estão presentes na escola e nas representações que ajudem a compreender essas diferenças no desempenho escolar das meninas e dos meninos. A análise do material aponta para a maneira feminina de exercer o magistério que atravessa a prática docente, para a profecia auto-realizadora referendada no critério de bom comportamento e para a estreita relação entre gênero e saber regulados pelos regimes de verdade.

RELAÇÕESDEGÊNERO-REPETÊNCIA-PROFESSORES

\section{ABSTRACT}

GOOD GIRLS, GOOD STUDENTS; SMART BOYS BUT MISBEHAVED. A longitudinal study has been following all the children born in Pelotas, Rio Grande do Sul, during 1982. Their academic background showed strong correlation with gender, even when eliminating other variables through statistical procedures. A study with 84 teachers tried to identify the process present at schools that could help to understand the differences between the girls' and boys' academic performances. The analysis points out to the female bias in teaching practice, to the self-fulfilling profecy reflected in the good-behavior criterion and to the close relationship between gender and knowledge determinated by the truth-regulations. 
Às vésperas do terceiro milênio, na era da informação e da mais sofisticada tecnologia, em meio ao debate dos diferentes paradigmas científicos, adentrando a pós-modernidade, continuamos a conviver com o malogro educacional que se produz dentro da escola, articulado com os crescentes processos de exclusão social. A persistência do chamado fracasso escolar, especialmente na escola pública, continua a desafiar as políticas educacionais e a indignar os educadores.

No Brasil, os índices de fracasso escolar atingem patamares impressionantes "da amostra de 100 alunos matriculados na I a série, apenas 3, isto é, 3\% vão se graduar sem nenhuma repetência em sua trajetória escolar, ou seja em oito anos" (Ribeiro, 1993. p.67). A persistirem essas taxas e tentando projetá-las para o futuro, somente no ano 2100 é que teremos $95 \%$ de uma geração com o $2^{\circ}$ grau completo (Ribeiro, 1993. p.70).

Em Pelotas (Rio Grande do Sul), no ano de 1996, o índice de evasão, no primeiro grau, na rede pública foi de $8 \%$, enquanto a reprovação atingiu $24 \%$, segundo dados obtidos no setor de informática da Secretaria de Educação do Rio Grande do Sul, em 1997. Considerando que o assim chamado fracasso escolar abrange tanto a reprovação como a evasão, constatamos que o índice de fracasso na rede pública atinge 32\%.

Um estudo de coorte' vem acompanhando todas as crianças nascidas na cidade de Pelotas, no ano de 1982, constituindo-se em estudo longitudinal (Victora, Barros, Vaughan, 1988). No início de 1993, quando as crianças tinham em média onze anos de idade, foi localizada uma amostra delas nas escolas da cidade. Os dados obtidos, nessa ocasião, demonstravam que $36 \%$ das crianças foram reprovadas pelo menos uma vez. A reprovação foi mais freqüente entre os meninos (4l\%) do que entre as meninas (30\%). Também considerou-se relevante o achado de que as crianças negras ${ }^{2}$ têm 2,5 vezes mais chances de reprovação do que as crianças brancas (Damiani, Barros, 1993).

Tendo em vista que um número significativo dessas crianças poderia encontrar-se fora da escola, um novo estudo foi realizado (Barros et al., 1995), utilizando visitas domiciliares. Buscou-se, então, verificar suas trajetórias no sistema escolar, incluindo evasão, taxa de reprovação, defasagem idade/série, desempenho escolar etc., associando as variáveis a cor, gênero, escolaridade dos pais, reprovação escolar dos irmãos, nível socioeconômico e outras.

Dentre os resultados obtidos nesse novo estudo, causam, sobremaneira, impacto os que dizem respeito aos determinantes de cor e de sexo sobre os índices de reprovação das crianças pesquisadas. Quanto ao sexo, o índice de reprovação foi maior entre os meninos (57\%) do que entre as meninas (42\%). Esse índice, contudo, eleva-se significativamente para

I. Uma coorte de idade representa o total de indivíduos com aquela idade na população da unidade geográfica analisada.

2. Todas as crianças nascidas em 1982 tiveram seus dados registrados pelos pesquisadores. A cor constituiu-se em uma das variáveis do estudo. Por ocasião da pesquisa de 1995, com visitas domiciliares a uma amostra de 723 crianças, o entrevistador anotou a cor da criança como ele a percebia. Tais anotações foram coincidentes com os registros arquivados no banco de dados. 
77\% quando se trata de meninos negros. Eliminada, por procedimentos estatísticos, a interferência de outros fatores de confusão como as diferenças socioeconômicas, a escolaridade da mãe, a presença do pai no lar, ainda assim o risco de reprovação dos meninos negros é quase três vezes maior do que seus colegas brancos (risco relativo $=2,8$ ), enquanto que entre as meninas, as que são negras têm um risco de reprovação quase duas vezes maior em comparação às meninas brancas (risco relativo $=1,7$ ).

Ampliando o estudo para além das crianças da coorte de 82, na tentativa de verificar a extensão do fenômeno, buscou-se dados referentes a quatro escolas da rede pública, todas de $1^{\circ}$ grau, sendo uma localizada em zona central e três, em diferentes bairros da cidade. Foram computados todos os casos de fracasso ${ }^{3}$ escolar dos alunos matriculados de $1^{\mathrm{a}}$ à $4^{\mathrm{a}}$ série nos anos de 1990 a 1992.

Como nos registros escolares, não existem anotações referentes à cor e ao sexo dos alunos, não foi possível computar as crianças negras, mas pelo nome de cada aluno computamos as meninas e os meninos, obtendo os resultados constantes no gráfico I.

\section{GRÁFICO I \\ FRACASSO ESCOLAR POR SÉRIE CONFORME O SEXO \\ EM QUATRO ESCOLAS DA REDE ESTADUAL (1990-92)}

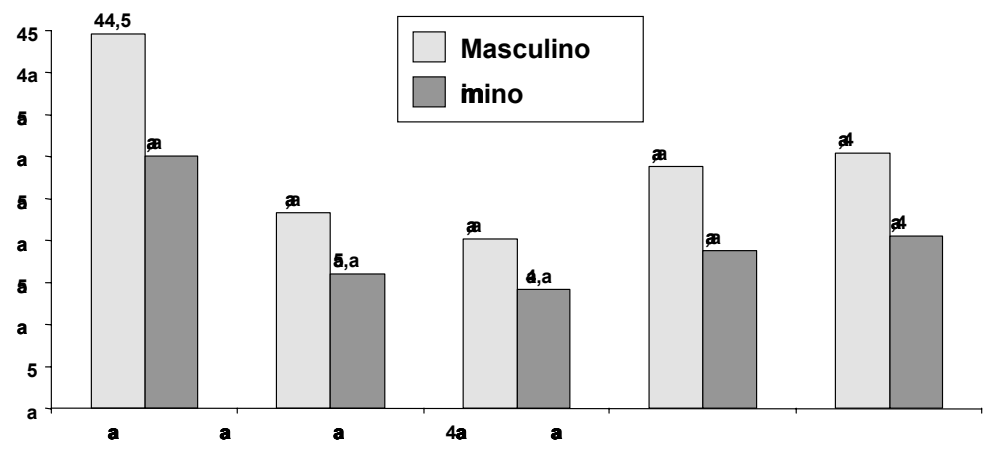

Fonte: Sistema de Informática Estadual/Divisão de Informática/Secretaria de Educação/RS, 1990-92.

Esses dados apontaram para a relevância do problema, indicando um viés de gênero, portanto, com um forte significado social e psicológico. Por que as diferenças de gênero na aprendizagem? Parece contraditório que os grandes escritores, advogados, políticos, jornalistas, poetas sejam, na sua maioria, homens, quando as meninas é que apresentam melhor desempenho nas primeiras séries escolares e na alfabetização. Elas é que gostam de escrever, de fazer composições, de registrar em "diários" etc., no entanto, eles é que se projetam na vida pública.

3. O termo fracasso é definido como "desastre, desgraça, mau êxito, ruína, perda, malogro" (Ferreira, s.d. p.654). No caso, refere-se à falta de êxito escolar, consubstanciado na reprovação e/ou evasão. 


\section{TENTANDO ENTENDER O FENÔMENO}

Os significativos índices de reprovação das crianças negras (Silva et al., 1996) e dos meninos orientaram o estudo no sentido de identificar os possíveis fatores determinantes destas reprovações, tomando-se como ponto de referência crianças da coorte de 82 com episódios de reprovação escolar. Dada a amplitude da questão, optou-se por proceder um recorte tendo como foco a percepção dos professores sobre o cotidiano das relações que se processam no interior da escola. Para isto, buscou-se identificar as representações ${ }^{4}$ dos professores sobre o desempenho escolar, os comportamentos considerados adequados/inadequados, a repetência e a previsão de aprovação/reprovação relacionados com sexo e cor dos alunos, as representações dos professores a respeito da própria profissão e de papéis de gênero, bem como suas percepções sobre a aprendizagem dos alunos e a participação dos pais no processo ensino-aprendizagem.

A investigação buscou, assim, identificar que processos estão presentes na escola e nas representações que possibilitem entender as diferenças no desempenho escolar relacionados à cor e ao gênero. $\bigcirc$ relato que fazemos, a seguir, descreve os resultados e a análise dos mesmos no que se refere à variável gênero ${ }^{5}$.

A escolha dos professores entrevistados foi definida por uma amostra intencional de alunos que compõem a coorte de 1982. A amostra foi estruturada da seguinte forma: foram sorteadas cem crianças, sendo 50\% meninos e 50\% meninas, 50\% crianças negras e 50\% crianças brancas, todas com pelo menos uma reprovação escolar. Destas cem crianças, 84 foram aproveitadas para compor a amostra por motivos variados (algumas deixaram de estudar, outras mudaram de cidade ou eram alunos de uma mesma professora).

Foram então mapeados, nas escolas, 465 professores destas 84 crianças, sendo 6\% professores negros e 10\% homens. Entrevistamos 84 professores (correspondendo a um professor de cada uma das crianças), usando-se como critério preferencial professores negros, homens ${ }^{6}$ e que tivessem o maior horário semanal de atuação com os alunos. Esta amostra dos 84 professores apresentou o seguinte perfil:

- idade média de 38 anos

- tempo médio de 15 anos na carreira

- $69 \%$ com curso superior

4. "Representação" é, neste contexto, entendida conforme a definição que detém amplo consenso de que Representações Sociais são "uma forma de conhecimento, socialmente elaborada e partilhada, tendo uma visão prática e concorrendo para a construção de uma realidade comum a um conjunto social" (Jodelet apud Sá, 1993. p.32).

5. O resultado do estudo referente à variável cor está publicado por Silva et al., 1996.

6. Considerando-se a baixa freqüência de professores homens e negros na composição do magistério, foi dada prioridade à presença desses professores numa amostra por quota, de maneira a serem super-representados. 
- 91\% atuando na rede pública (sendo 63\% da rede estadual)

- área de atuação: $28 \%$ currículo por atividades

\section{4\% matemática \\ | $4 \%$ português}

- salário médio: 4,5 salários mínimo

Apesar de se buscar, intencionalmente, professores homens e negros, a amostra ficou composta de setenta (83\%) mulheres e quatorze (17\%) homens, e de 63 (75\%) professores brancos e 2 I (25\%) professores negros. Mesmo com tal intencionalidade, a amostra contou com somente três professores homens e negros.

A entrevista foi o principal instrumento utilizado para a coleta de dados, buscando-se obter, por intermédio das falas, elementos que possibilitassem apreender as representações que os professores têm a respeito de seus alunos, seu trabalho, diferenças identitárias. Entende-se que tais representações estruturam as relações, os comportamentos, as expectativas, as interações sociais (Alves-Mazzotti, 1994), enfim, são definidoras do sucesso ou fracasso escolar.

As entrevistas foram do tipo semi-estruturada (Minayo, 1992, Martins, Bicudo 1989), buscando-se obter informações e opiniões a respeito da temática, bem como detectar os sentimentos, representações, valores, atitudes, opiniões, enfim, a subjetividade desses professores.

O que torna a entrevista instrumento privilegiado de coleta de informações para as ciências sociais é a possibilidade de a fala ser reveladora de condições estruturais, de sistemas de valores, normas e símbolos (sendo ela mesma um deles) e ao mesmo tempo ter a magia de transmitir, através de um porta-voz, as representações de grupos determinados, em condições históricas, sócioeconômicas e culturais específicas. (Minayo, 1992. p.I I0)

Utilizou-se um questionário com questões fechadas acompanhadas de justificativa sobre a opção escolhida. As entrevistadoras registraram, em um diário de campo, todas as observações a respeito da receptividade da escola, do professor, suas reações, silêncios, exclamações, comentários, as formas de expressão, gestos, sinais não verbais, reações, hesitações (Thiollent, 1982). As entrevistadoras foram previamente treinadas e o instrumento aprimorado após estudo piloto.

\section{REVENDO ESTUDOS PERTINENTES}

Gênero, neste estudo, está sendo definido como a construção social e histórica de sujeitos femininos e masculinos que se processa de maneira diferenciada, dentro de uma mesma sociedade, "de acordo com diferentes modelos, ideais, imagens que têm as diferentes classes, raças, religiões etc. sobre mulher e sobre homem" (Louro, 1992. p.56). 
Numa perspectiva foucaulteana, gênero significa o saber a respeito das diferenças sexuais. As sociedades e as culturas produzem uma compreensão sobre as relações entre homens e mulheres.

Tal saber não é absoluto ou verdadeiro, mas sempre relativo, ele é produzido de maneira complexa no interior de epistemes que têm, elas próprias, uma história autônoma (ou quase)... O saber é um modo de ordenar e, como tal, não antecede a organização social mas é inseparável dela... Gênero é a organização social da diferença sexual... é o saber que estabelece significados para as diferenças corporais. (Scott, 1994. p. I3)

Apesar de no Brasil, como em inúmeros outros países, o magistério ser uma atividade profissional predominantemente feminina, há poucas investigações que articulem os estudos sobre gênero com a profissão de professor. $\bigcirc$ conhecimento produzido pelos estudos sobre a mulher raramente incorporam a pesquisa educacional (Rosemberg, Amado, 1992).

O processo de trabalho docente tem-se tornado sujeito a forte proletarização, e, em toda a categoria ocupacional, as mulheres estão mais sujeitas a esse processo do que os homens, sendo necessário, para entender os efeitos dessa proletarização sobre o próprio trabalho docente, perceber as conexões entre as duas dinâmicas: classe e gênero (Apple, 1995).

A profissão docente é eminentemente feminina, não só pela predominância numérica, mas, principalmente pela condição social da mulher que estende para a escola seu papel feminino, vivenciando o espaço da escola como se fosse um espaço privado (extensão da casa) e não público. Tal posição reduz a professora ao parentesco de tia, tirando-lhe o dever de ensinar e ser professora e reduzindo sua ação a uma amorosidade maternal (Novaes, 1984).

Enguita ( 1989), ao constatar que as meninas apresentam melhor desempenho escolar até os doze anos e que, após essa idade, há uma inversão dessa tendência, retoma a idéia generalizada de que as meninas percebem que a educação não tem para elas caráter instrumental para ascender socialmente, uma vez que seu futuro será mesmo o de dona-decasa. Argumenta que as meninas são mais submissas, ou foram educadas para submeter-se à autoridade, sendo mais cuidadosas em seu trabalho, ajustando-se, assim, à disciplina da escola. Os meninos, ao contrário, são mais rebeldes, independentes, criativos. Prefere, porém, a interpretação de que, enquanto a família se organiza em torno da superioridade indiscutida do gênero masculino sobre o feminino, a escola tem uma organização mais democrática, tratando a todos com igualdade. Assim as meninas, por um mecanismo de compensação, apegam-se a uma instituição que as trata como iguais, correspondendo aos seus padrões e prescrições, até o momento em que percebem que a eficácia da escola não é tão grande a ponto de inverter as oportunidades futuras das mulheres na família e no trabalho.

Também a psicopedagoga argentina Alícia Fernandez ( 1994) observa que a maioria da população infantil trazida à consulta por apresentar fracasso escolar ou dificuldades de aprendizagem, estava composta por meninos (num total de quinhentos casos de crianças com menos de quatorze anos, $70 \%$ eram meninos). Este fenômeno é analisado pela autora a 
partir da relação entre as atividades docentes e o papel de gênero feminino, entendendo que para construir-se como ensinante, a professora-mãe precisa omitir sua condição sexual. A autora observou, também, que a maioria da população infantil trazida à consulta por apresentar fracasso escolar ou dificuldades de aprendizagem, estava composta por meninos (num total de quinhentos casos de crianças com menos de quatorze anos, 70\% eram meninos).

Associa, ainda, a maior incidência de insucesso escolar nos meninos à repercussão, na subjetividade de homens e mulheres, da superdimensão que tradicionalmente tem-se dado ao lugar da mãe (e da professora) e a conseqüente desqualificação do lugar e do papel do pai no processo de educação dos filhos, "... as formas culturais estabelecem uma identificação entre ser mulher e ser mãe e uma conseqüente falta de relação entre ser homem e ser pai" (Fernandez, 1994. p.22). A constituição da subjetividade feminina tem a maternidade incorporada - as mulheres têm de ser mães. Essa forma cultural não estabelece, para o homem, o mandato da paternidade. Ambos os gêneros são, assim, privados de desfrutarem, o homem de sua paternidade e a mulher de sua sexualidade.

Meninos e meninas recebem educação muito diferente, embora sentados na mesma sala, lendo os mesmos livros didáticos, ouvindo o mesmo professor. É o que Sadker (1995) tenta detectar nas formas sutis e aparentemente invisíveis com que os professores interagem com seus alunos/as. Suas observações buscam rastrear desde currículos, livros didáticos, estórias infantis, personagens históricos até o tipo de pergunta, os estímulos e reforços utilizados pelos professores, a organização do espaço etc.

Revisitando os clássicos estudos de Sears et al. ( 1 957) sobre criação de filhos, percebemos que, ao investigar os jeitos, cuidados e atitudes das mães na criação dos filhos, há uma supervalorização da figura da mãe, em detrimento do papel do pai. E as práticas de criação de filhos determinam a natureza do desenvolvimento de uma criança, sendo que a mãe, por sua disponibilidade e permanente solicitude, aliviando desconfortos e gratificando desejos, estabelece profundos vínculos com o filho. Esta relação de dependência inicial com a mãe marca fortemente os processos posteriores de aprendizagem.

Os trabalhos de maior divulgação sobre o desenvolvimento infantil a partir de um referencial teórico psicanalítico (Klein, 1969; Winnicott, 1966; Buxbaum, 1959; Spitz, 1960; Mannoni, 1976; Dolto, 1977) centram sua compreensão do processo de estruturação psíquica da criança na relação entre mãe e filho, secundarizando o papel do pai. A ênfase na importância das primeiras relações entre mãe e filho, ao mesmo tempo que humanizou o conceito de infância, acarretou, para a mulher, um modelo de sacrifício para dar sustentação à maternidade e tornou-a responsável pela saúde física e mental dos filhos.

Quanto à professora que teve socialmente constituída sua subjetividade feminina, foiIhe atribuído o desejo maternal, tendo-lhe sido negados outros desejos constitutivos da subjetividade feminina: o desejo hostil, o desejo de saber e o desejo de poder (Burin, 1989). Tais desejos, que têm como correlatos os comportamentos de independência, competitividade, ambição, são incompatíveis com os modelos de feminilidade vigentes. Desta forma, tais 
desejos só podem ser acionados no âmbito privado das atividades domésticas, assumindo formas que vão da "mulher mandona" a comportamentos de dissimulação e sedução. Ou na escola, como extensão do privado/doméstico, assumindo a forma da "professora gritona", "assustadora" ou, ainda, comportamentos mais dissimulados de controle, como o de impedir a autoria do aluno e o de reprovar.

Essas referências indicam que estamos diante de uma questão multifacetada. Em nossa investigação, buscamos estabelecer possíveis conexões entre o desempenho escolar dos alunos (sujeitos aprendentes) e as relações de gênero que estão presentes tanto nos aprendizes como nos que ensinam. Entendemos que tais relações dão significado aos atos de aprender e de conhecer; e que o nãoaprender, as dificuldades - fraturas - podem representar, em nível simbólico, que os processos cognitivos, por alguma razão, encontram-se "aprisionados" (Fernández, 1990).

\section{AS REPRESENTAÇÕES DAS/OS PROFESSORAS/ES}

material obtido nas entrevistas com docentes é apresentado por meio de dados quantitativos (freqüências) e da análise do conteúdo das respostas, justificativas, comentários etc., relacionando as falas com os dados e tentando compreendê-las a partir dos autores em quem buscamos suporte teórico.

\section{Do desempenho das meninas e dos meninos}

Considerando que o objetivo central desta investigação foi identificar os possíveis determinantes do diferente desempenho escolar entre as meninas e os meninos, uma das perguntas iniciais apresentadas às/aos ${ }^{7}$ professoras/es foi relativa à percepção e à compreensão que têm sobre quem é mais reprovado: as meninas ou os meninos? A reação inicial foi de bastante surpresa, logo após de dúvida, buscando lembrar, como quem vai rememorando, que são os meninos. Utilizaram expressões do tipo "Nunca pensei nisto! Deixa-me pensar" 8 ... As respostas obtidas estão descritas na tabela I.

TABELA I

OPINIĀO DAS/OS PROFESSORAS/ES A RESPEITO DA REPROVAÇÃO DOS/AS ALUNOS/AS, SEGUNDO O SEXO

\begin{tabular}{l|r|r}
\hline Quem é mais reprovado & $\mathbf{n}$ & $\%$ \\
\hline meninos & 54 & 64 \\
meninas & 6 & 7 \\
sem diferença & 21 & 25 \\
não sabe & 3 & 4 \\
Total do professores & 84 & 100 \\
\hline
\end{tabular}

Fonte: Victora, Barros, Vaughan (1988).

7. Compartilhando das justificativas de Hypólito (1995), optamos pela forma a/o, professoras/es etc., com a colocação do feminino na forma inicial, dada a presença majoritária das mulheres no magistério e que não aparecem nos estudos devido à utilização do masculino genérico (Carvalho, Vianna, 1995).

8. Nos relatos que se seguem, as falas das/os entrevistadas/os serão destacadas por aspas. 
Havíamos anteriormente identificado com surpresa, como refere Madeira (1997), que também os órgãos educacionais desconhecem essa diferença, nem há registro de tais dados em seus assentamentos. O fato é revelador da inexistência de estudos sobre as causas da reprovação dos alunos. Do contrário, tal evidência já teria sido detectada como uma das variáveis problemáticas.

As justificativas da diferença de desempenho expressam a percepção de que "os meninos são mais inteligentes, porém, indisciplinados; enquanto as meninas são atentas e aplicadas, mas menos inteligentes". Traçam, portanto, um perfil dos alunos e das alunas, delineando as características que enxergam e ressaltam. Ao mesmo tempo que percebem essas características ancorando-as nas suas próprias concepções e representações, vão também construindo contornos e assim dando forma aos próprios comportamentos de seus/ suas alunos/as.

Outras caracterizações dos comportamentos indicam "as meninas como mais responsáveis, dedicadas, estudiosas, interessadas, sensíveis, atentas". Enquanto "os meninos são malandros, não têm hábitos de estudo, não ficam em casa para estudar, saem para jogar bola, faltam às aulas, são dispersivos, têm interesses fora da escola, são agitados, não prestam atenção, ainda que mais inteligentes".

Ao responderem sobre quem consideram mais aplicado/a, as/os professoras/es, ao contrário da reação anterior, não titubearam: $80 \%$ expressou com muita segurança que são as meninas, enquanto apenas $2 \%$ indica os meninos. A preocupação com o cotidiano da sala de aula faz com que seja maior o desejo de que o/a aluno/a corresponda às prescrições e determinações, do que com o processo de aprendizagem ou com a construção do conhecimento.

\section{Do comportamento das meninas e dos meninos}

"As meninas são mais controladas.... As meninas são mais conversadoras, mas os meninos são mais agitados, não param sentados." Os professores comentam:

...antigamente, as meninas tinham melhor comportamento, mas, hoje, as coisas têm mudado. [... ] Hoje está evoluindo para a igualdade....Parece até mentira, mas quase que são os meninos que se comportam melhor...As meninas também estão ficando agressivas, antes eram mais pacatas.

Expressam, assim, a expectativa de que se cumpra o padrão social de comportamento previsto para cada gênero. "Nem parece uma menina"... é o veredito proferido pela professora que se arroga como aquela que define o que é e não é ser mulher. "Quando a menina não cumpre com os quesitos escolares, tem a sua condição sexual questionada" (Abramowicz, 1995. p.54). O bom comportamento em sala de aula, na opinião das/os entrevistadas/os, é mostrado na tabela 2. 
TABELA 2

OPINIÃO DAS/OS PROFESSORAS/ES QUANTO AO COMPORTAMENTO DE MENINOS/AS EM SALA DE AULA

\begin{tabular}{l|r|r}
\hline Quem tem bom comportamento & $\mathbf{n}$ & $\%$ \\
\hline meninas & 49 & 58 \\
meninos & 2 & 2 \\
sem diferença & 33 & 40 \\
Total de professores & 84 & 100 \\
\hline
\end{tabular}

Fonte: Victora, Barros, Vaughan (1988).

\section{Das meninas e meninos negros}

As falas expressam:

...as meninas negras têm muitas dificuldades; mas são mais lutadoras e conseguem bom rendimento no esporte. As crianças negras são menos motivadas por seus pais e os meninos são encaminhados para trabalhar... São mais revoltados, estudam menos, têm problemas na família... Das $6^{\text {as }}$ séries em diante têm poucos negros porque já caíram fora.

Expressam, assim, o processo de exclusão. Observa-se surpresa e pouca percepção nas duas questões que envolvem reprovação associada tanto à variável gênero como à variável cor. A dificuldade, contudo, é ainda maior no que diz respeito à variável cor, tanto que a resposta não sabe atinge $4 \%$ na relação reprovação $\times$ sexo, enquanto na relação reprovação x cor atinge $26 \%$. Tais resultados são mostrados na tabela 3.

TABELA 3

OPINIÃO DAS/OS PROFESSORAS/ES QUANTO À REPROVAÇÃO DE ALUNOS/AS NEGROS/AS

\begin{tabular}{l|r|r}
\hline Quem é mais reprovado & $\mathrm{n}$ & $\%$ \\
\hline meninos negros & 27 & 32 \\
meninas negras & 4 & 5 \\
sem diferença & 29 & 35 \\
não responderam & 2 & 2 \\
não sabem & 22 & 26 \\
Total de professores & 84 & 100 \\
\hline
\end{tabular}

Fonte: Victora, Barros, Vaughan (1988)

\section{Dos territórios das meninas e dos meninos}

Fica evidente a percepção das diferenças de gênero nas aptidões e interesses: meninas preferem Português e Artes, e meninos preferem Educação Física e Matemática. $\bigcirc$ gosto pela Educação Física nos meninos atingiu o percentual mais alto de todas as respostas. Com 
relação às meninas, pode-se observar uma certa dúvida (não sabe 27\%) mas nos meninos a soma das duas primeiras opções escolhidas (Educação Física e Matemática) atinge 50\% das respostas (ver quadro I).

\begin{tabular}{|c|c|}
\hline $\begin{array}{l}\text { QUADR } \\
\text { OPINIÃO DAS/OS PROFESSORAS } \\
\text { EM QUE MENINAS E MENINQ }\end{array}$ & $\begin{array}{l}\text { ANTO À DISCIPLINA } \\
\text { MAIS FACILIDADE }\end{array}$ \\
\hline Meninas & Meninos \\
\hline $\begin{array}{l}\text { Português - } 23 \% \\
\text { Artes - } 13 \% \\
\text { não sabe - } 27 \% \\
\text { não há diferença - I7\% } \\
\text { outras - } 20 \%\end{array}$ & $\begin{array}{l}\text { Educação Física - 32\% } \\
\text { Matemática - } 18 \% \\
\text { não sabe - } 19 \% \\
\text { não há diferença - 13\% } \\
\text { outras - 18\% }\end{array}$ \\
\hline
\end{tabular}

Fonte: Victora, Barros, Vaughan (1988).

Os comentários sobre a maior facilidade das meninas e meninos nas diferentes disciplinas expressam:

...as meninas têm mais dificuldade de raciocínio e preferem escrever cartas, poesias, versos, são detalhistas e têm facilidade para decorar, desenhar e para Artes. Os meninos, por seu lado, gostam de 'continhas', raciocínio, jogos, atividades práticas. Não gostam de decorar, têm dificuldade quando precisam estudar. Não trazem material para aula. Têm 'paixão' pela Educação Física e são 'loucos' por bola.

Segundo Walkerdine:

...a naturalização da razão como o ponto de chegada de uma progressão dos estádios de desenvolvimento coloca a Mulher como constantemente ameaçando esta meta. Ela é constantemente condenada por não raciocinar e igualmente reprovada se o faz. Seu raciocínio é visto como constituindo uma ameaça à masculinidade raciocinante. (1995. p.213)

As falas das/os professoras/es são definidoras dos saberes próprios das meninas e dos meninos, confirmando que os meninos "têm dificuldade de estudar, não gostam de decorar, só querem jogar". Além de expressarem uma leitura atravessada do viés de gênero, revelam concepções do que é aprender e qual comportamento está pressuposto neste ato.

As respostas à questão sobre quem apresenta melhor desempenho escolar são enfáticas: $66 \%$ indicam que as meninas, enquanto apenas 3\% respondem que são os meninos. Explicam:

....as meninas são mais estudiosas, mais cobradas em casa, são organizadas, caprichosas e responsáveis. Gostam mais da escola (42\%), ficam sentadas, curtem as amigas e namorados. Os meninos gostam do ambiente escolar, mas não gostam da sala de aula, só querem jogar, são muito críticos.

Informam não haver planejamento de atividades escolares diferenciadas para meni- 
nas e meninos (95\%). Poucos se referem a alguma diferença nas atividade de Educação Física e em Artes. Observa-se que Educação Física é uma atividade que envolve corpo, movimento, ação; Artes envolve criatividade, habilidade manual, sensibilidade, confirmando as características de gênero referidas.

\section{Da participação da família}

Sobre o envolvimento da família nas atividades escolares e no acompanhamento do processo de escolarização, afirmam que nas reuniões de pais o comparecimento das mães é maior (94\%). São também elas ou outra pessoa que auxiliam na realização dos temas, em casa (69\%).

As atividades relativas à escola como temas, disciplina, organização do material e o próprio processo de aprendizagem são revestidas de um caráter feminino e por isso mais próprias às mulheres. Dessa forma, a escola tende a estreitar relações com as mães, dificultando a inserção do pai. Considerando a predominância feminina no magistério, instala-se como que um pacto de mulheres.

\section{Da repetência}

Com relação à experiência de trabalho com alunos repetentes, as respostas obtidas foram as seguintes: $95 \%$ das/os professoras/es têm ou já tiveram alunos repetentes em aula; $88 \%$ informaram que não planejam atividades diferenciadas para eles; $67 \%$ afirmam que é fácil prever o resultado que o aluno apresentará ao final do ano, 29\% acham difícil prever, e 4\% consideram impossível prever.

A amostra deste estudo teve como ponto de partida crianças da coorte de $82 \mathrm{com}$ pelo menos um episódio de reprovação, portanto, todas/os as/os professoras/es entrevistadas/os tinham em sua turma uma dessas crianças reprovadas. Contudo, à pergunta se sabiam que seu aluno já fora reprovado, responderam: sim (57\%), não sabe (27\%), não foi reprovado (16\%). Logo, muitas/os professoras/es desconheciam que seu aluno tinha história de reprovação, e muitos ( $16 \%$ ) chegam a afirmar que não foi reprovado. A maioria, por sua vez, aponta a própria criança e a família (57\%), seguidas da escola e da turma (I 3\%), como responsáveis pela reprovação, sendo que $28 \%$ não souberam responder. Sobre o trabalho pedagógico que desenvolvem com os alunos em sala de aula, $88 \%$ dos professores dizem não haver nenhuma diferenciação para os alunos repetentes. Esse dado, associado ao fato de muitas/os professoras/es desconhecerem se o aluno já foi ou não reprovado, sugere que reprovação significa uma simples repetição. Qual a lógica dessa "pedagogia da repetência" senão refazer ou recuperar os conteúdos e habilidades não adquiridos? Pode-se assim entender os dados que demostram que uma criança repetente tem a metade da chance de ser aprovada no ano seguinte, quando comparada a uma ingressante na mesma série (Ribeiro, 1993). A repetência 
é, em si mesma, uma das principais causas da repetência. Além dessas sucessivas reprovações, a investigação de Barros et al. (1995) identificou "famílias" de repetentes, ou seja, casos em que as histórias de reprovação se reproduzem com todos os filhos. Essas sucessivas reprovações, na maior parte das vezes, produzem a estigmatização do aluno, que passa então a ser visto como diferente ou deficiente. Tal fato adquire contornos perversos quando associado ao nível socioeconômico desfavorável e à cor negra, em que a reprovação mais se concentra, pois que consubstancia o "mito" da incapacidade do aluno oriundo das classes trabalhadoras ("seus cérebros ficam atrofiados, são mal alimentados e não tomam fortificantes").

\section{Da profecia}

Solicitada/o a fazer uma previsão do resultado que tal aluno reprovado apresentará ao final do ano (o estudo foi realizado no mês de julho) a/o professora/or prevê que será aprovado (57\%), será reprovado (20\%), não sabe (20\%). Cruzando essa previsão com o gênero do/a aluno/a, identificamos a "profecia" de que os meninos vão "rodar" (70\%) de maneira mais significativa do que as meninas (44\%), mas não observamos diferenças entre os alunos brancos e os negros. No entanto, ao se referirem à reprovação já ocorrida, as/os professoras/es sabem que alunos negros "rodaram". Sobre a permanência do aluno na escola, apesar dos freqüentes insucessos, justificam ser por "exigência dos pais, 49\%, por causa da merenda escolar, 22\% e pelo desejo de aprender, 13\%". Sem dúvida que o imaginário dos professores prioriza a escola como lugar no qual se vai obrigado, por exigência, ou lugar em que se vai prioritariamente para comer. Esse imaginário, que pouco valor dá ao desejo de conhecer do aluno, potencializa-se como um significante que determina práticas pedagógicas, constitui e faz a medição das relações e, desta forma vai, certamente, produzindo subjetividades.

\section{Da profissão}

Quanto à escolha da profissão-professora/or, as respostas centraram-se em: gostar de ensinar e vocação (71\%). Sobre a predominância feminina no magistério das séries iniciais, responderam: profissão própria para a mulher, pois tem mais jeito (63\%). Apenas I4\% apontaram o aviltamento salarial. Comentam ser:

..."tradição cultural e histórica" [a presença feminina no magistério]; "que a mulher tem mais paciência e instinto materno; que são detalhistas e mais concentradas. $\bigcirc$ homem [com tais predicativos] seria visto como florzinha e homossexual... [a profissão] não dá status...Preenche a vida das donas de casa."

As características atribuídas à profissão são as mesmas atribuídas à mulher, com ênfase nos atributos maternais. São também as mesmas características pelas quais se justifica que a 
menina é melhor aluna, gosta mais da escola, é menos reprovada.

Sobre renda e remuneração, metade das/os professoras/es contam com a renda de outra pessoa da família, quase sempre esposas/os que, em 34\% das situações, têm renda maior. Mesmo assim, 25\% percebe o maior salário da família. E 97\% não pensa em ter outra profissão.

\section{Das tarefas públicas e privadas}

Considerando-se que atualmente membros da família saem para trabalhar/estudar pedimos para as/os professoras/es indicarem, de uma lista de atividades referentes ao cotidiano familiar, quem, costumeiramente, as realiza (homem, mulher, ambos). As respostas corroboram a representação do senso comum sobre as funções e papéis de gênero. As atividades de caráter público, como ir ao supermercado, educar os filhos, têm uma participação maior de ambos. Apesar de um percentual significativo da alternativa ambos nas atividades de cuidar dos filhos e responsabilizar-se por sua educação, nas demais tarefas que se constituem, na prática, em fazer algo (cuida-se dos filhos preparando sua alimentação, levando ao médico, auxiliando nas tarefas escolares, lavando sua roupa) a incidência recai sobre a mulher. As tarefas do lar bem como as da escola (temas, reuniões na escola, levar e trazer da escola) são identificadas como funções do gênero feminino; a maior rejeição à participação masculina está nas tarefas de caráter privado e consideradas socialmente menos nobres (menor status social) como lavar a roupa e a louça.

O mundo do trabalho é, sem dúvida, um dos espaços mais significativos para analisar as diferenças de gênero. Atividades que tradicionalmente eram desempenhadas por mulheres e consideradas tipicamente femininas, quando se tornam mecanizadas e remuneradas, passam a ser exercidas por homens, acrescidas, em muitos casos do qualificativo de científicas e tecnológicas. As principais profissões apontadas como próprias para mulheres e para homens estão descritas no quadro 2.

\section{QUADRO 2}

PROFISSÕES APONTADAS PELAS/OS PROFESSORAS/ES COMO PRÓPRIAS PARA MULHERES E HOMENS

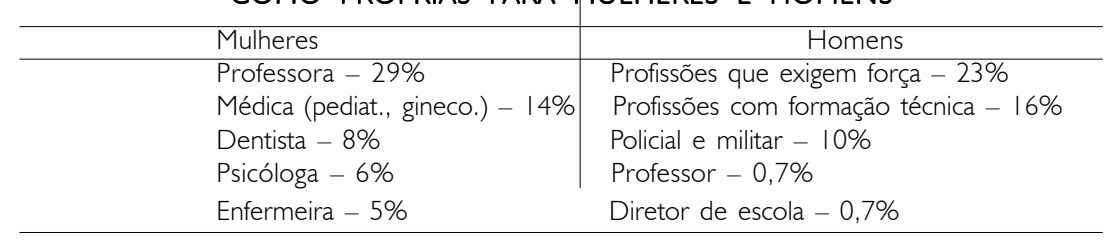

Fonte: Victora, Barros, Vaughan (1988).

Para a mulher são indicadas profissões identificadas com funções do lar e maternas e que supõem cuidar; as que se constituem em construir, planejar, oferecer segurança são 
percebidas como masculinas. Professora é indicado para a mulher com quase $30 \%$, para o homem não chega a I\%. A função de diretor de escola é lembrada somente para o homem.

Quanto ao comportamento dos/as alunos/as com relação à sexualidade, as/os professoras/es percebem que há diferenças, destacando que as meninas têm mais informações sobre sexo (40\%) e menos experiência (26\%), enquanto os meninos têm menos informação (23\%) e mais experiência (46\%). Esta opinião coincide com os achados do estudo sobre epidemiologia das relações sexuais em adolescentes no sul do Brasil (Béria et al., 1996).

\section{CONCLUSÕES}

Os cuidados da criança pequena realizados, em nossa cultura, maciçamente apenas pela mãe têm, com certeza, conseqüências para a construção dos sujeitos e repercussões em seus processos de aprendizagem. E o magistério é visto como uma extensão da prática maternal ou exercício da maternidade ("paradigma do trabalho doméstico", na expressão de Rosemberg, 1992. p. 173), entrelaçando-se, assim, o "doméstico e o profissional, o privado e o público". Esse pode ser um aporte para a compreensão da maior reprovação dos meninos.

A condução do processo educativo, como socialização da criança, desde a instituição familiar até a escola, está permeada de estereótipos de gênero, definindo - ou seja, autorizando ou interditando - determinados campos de conhecimento e de ação, como femininos ou masculinos. Assim, são sexuados os saberes, as áreas de conhecimento, os comportamentos e formas de expressão, a sexualidade, os desejos, etc. Entende-se, pois, que a maneira feminina de exercer o magistério, nas séries iniciais, favorece e valoriza o desempenho escolar das meninas.

As informações das/os professoras/es mesclam-se com suas próprias convicções. Quando opinam sobre as tarefas familiares a serem divididas entre homem e mulher, revelam seus próprios estereótipos e preconceitos, pois que as representações, ao mesmo tempo que dão sentido às vivências, vão também produzindo subjetividades. Além disso a prática docente, para além da ordenação didático-pedagógica, está atravessada de conteúdos culturais, institucionais, sociais, psicológicos que constituem o próprio imaginário das/os professoras/es.

A queixa de que a família não se interessa pelos estudos das crianças, que não auxilia (especialmente a mãe) na realização dos temas e tarefas escolares, parece deslocar o processo ensino-aprendizagem da escola para a casa. E a mãe, por não se envolver suficientemente com a escolarização do filho/a, passa a ser responsabilizada pelo fracasso escolar, do mesmo modo como é responsabilizada por qualquer fracasso do filho, fracasso este produzido "através de um vínculo inadequado entre mãe e filho ou através da ausência prolongada da mãe, ou, ainda, do fracasso da mãe na infância" (Walkardine, 1995. p.213).

Embora a escola como instituição tenha objetivos explícitos e "bem-intencionados", funciona com muito mais eficiência pelas redes de relações, pelo não-dito e não-explicitado, pelos rituais e simbolismos. É nesse cadinho que o/a aluno/a vai-se construindo como sujei- 
to, como homem ou mulher.

Há que se considerar, ainda, que, ao ingressar na escola, a criança já traz uma representação dos papéis de aprendiz e professor, de homem e de mulher vivenciados nas relações familiares. Tal representação contempla uma diferença importante que é a de aluno e aluna. $\bigcirc$ que, por exemplo, os pais esperam de seu filho para que seja considerado um bom aluno? $\bigcirc$ que, para o pai, é mais significativo, que seu filho traga boas notas e um parecer de aluno "bem-comportado" ou que as notas sejam sofríveis ou até insuficientes, mas que ele se saia bem como aquele que "não leva desaforo para casa" e, por isso, não é chamado de maricas?

É significativo que não se encontrem nem nas escolas nem nos órgãos coordenadores do ensino os resultados escolares organizados por sexo. As/os professoras/es entrevistadas/ os também "não sabem" que meninos são mais reprovados do que as meninas. Sabem, contudo, dizer com antecipação os alunos que serão aprovados. Poderíamos supor que nesta "previsão" está embutida a "profecia auto-realizadora" (Rosenthal, Jacobson, I981. p.270). E de que forma se opera esse processo? Através do relacionamento professor/aluno, dos sentimentos que, de alguma forma, transparecem, pelas manifestações de agrado ou desagrado, do reforço oferecido aos comportamentos desejados. Assim vão sendo construídos os contornos das trajetórias escolares. Tratando do fracasso escolar, Nicolaci ( 1 987) se refere ao poder dos "rótulos" na definição de trajetórias. E o "rótulo" homem, mulher, tem anterioridade à própria escolarização, sendo, por isso mesmo, de muita força.

Tradicionalmente as concepções de ensino pressupõem que a/o professora/or é quem sabe, ela/e é que detém a autoria do conhecimento. $\bigcirc$ aluno conforma-se à expectativa do professor, submetendo-se ao que se espera dele. Desse modo, a profecia auto-realizadora é sempre autoritária, pois, prevendo tanto o sucesso como o fracasso do aluno, este será sempre anulado em sua resposta.

Os estudos sobre sucesso e fracasso escolar têm se preocupado muito menos com o aluno bem-sucedido porque ele não é problema. No entanto, esta é uma criança passível de um penoso processo de adaptação (Nicolaci, 1987), muitas vezes abrindo mão de seus referenciais, vivendo conflitos entre os valores de seu contexto e os da escola, entre os seus pares e a/o professora/or.

Para a subjetividade da menina, por exemplo, o processo de construir-se como aluna bem-sucedida é duplamente penoso: primeiro, porque para submeter-se às regras da escola precisa assumir os comportamentos esperados de menina bem comportada e segundo, porque, após a adaptação, deverá sair de cena, abrindo mão do papel de boa aluna para que os meninos passem a ocupar os lugares de destaque na vida pública.

Por outro lado, que mecanismos se produzem na relação da professora com seus/ suas alunos/as, pois que ela própria mulher também, está sujeitada a processos de submissão, enquanto constrói sua identidade de gênero? "É nas práticas sociais que somos produzidos da forma que somos e nos tornamos as pessoas que somos, reguladas como são, essas práticas, 
no discurso e através das 'verdades'” (Walkerdine, 1995. p.220).

Reforça-se, por fim, a estreita relação entre gênero e saber. É diferente o movimento do menino e da menina diante do conhecimento. Éa (mulher) professora quem define o que e como ensinar, o que avaliar, o que aprovar. $\bigcirc$ aprender nas séries iniciais muitas vezes se reduz a copiar, reproduzir, imitar, registrar, calar, não se autorizar o conhecimento, culpabilizarse pela autoria. E esse é um movimento mais "adequado" às meninas e recusado pelos meninos que são o diferente da professora. Podemos concluir, portanto, que o melhor desempenho escolar das meninas está referenciado muito mais no bom comportamento do que na construção do conhecimento.

\section{REFERÊNCIAS BIBLIOGRÁFICAS}

ABRAMOWICZ, A. A menina repetente. Campinas: Papirus, 1995.

AFONSO, L. Gênero e processo de socialização em creches comunitárias. Cadernos de Pesquisa, São Paulo, n.93, pl2-21, maio 1995.

ALVES-MAZZOTTI, A.J. Representações sociais: aspectos teóricos e aplicações à educação. Em Aberto. Brasília, n.61, p.60-78, 1994.

APPLE, M. Trabalho docente e textos: economia política das relações de classe e de gênero em educação. Porto Alegre: Artes Médicas, 1995.

BARROS, F. et al. Fracasso escolar em uma coorte de crianças em Pelotas (RS): a influência do gênero, raça, estrutura familiar e situação sócio-econômica. Pelotas: UFPel, 1995. (mimeo.)

BÉRIA, J. et al. Epidemiologia das relações sexuais e do uso de preservativo em adolescentes escolares em um centro urbano no Sul do Brasil. Revista Brasileira de Doenças Sexualmente Transmissíveis. São Paulo, n. I, p.3-8, 1996.

BUXBAUM, E. Comprenda a su hijo: una guia para los padres. Buenos Aires: Paidós, 1959.

BURIN, M. Familia y subjetividad feminina: la madre y su hija adolescente. In: GILBERT, E., FERNANDEZ, A.M. La mujer y la violencia invisible. Buenos Aires: Sudamericana, 1989.

CARVALHO, M.P, VIANNA, C.P. Movimentos sociais por educação: a visibilidade dos gêneros. Cadernos de Pesquisa, São Paulo, n.93, p.32-9, maio 1995.

DAMIANI, M., BARROS, F. Fracasso escolar associado às variáveis cor, gênero, estrutura familiar e situação sócio-econômica. Pelotas: UFPel, 1993. (mimeo.)

DOLTO, F. Psicanálise e pediatria. Rio de Janeiro: Zahar, 1977. 
ENGUITA, M. F. Educação e teorias da resistência. Teoria e Debate, Porto Alegre, v. I 4 n. I, p.3-16, 1989.

FERNÁNDEZ, A. A Inteligência aprisionada. Porto Alegre: Artes Médicas, 1990.

. A Mulher escondida na professora. Porto Alegre: Artes Médicas, 1994.

FERREIRA, A. B.H. Novo dicionário da língua portuguesa. Rio de Janeiro: Nova Fronteira, s.d.

HYPÓLITO, A. Relações de gênero e de classe social na análise do trabalho docente. Cadernos de Educação FaE/UFPel, Pelotas, n.4, p.5-18, 1995.

KLEIN. M. et al. A Educação de crianças à luz da investigação psicanalítica. Rio de Janeiro: Imago, 1969.

LOURO, G. L. Uma leitura da história da educação sob a perspectiva do gênero. Teoria \& Educação, Porto Alegre, n.6, p.53-67, 1992.

MADEIRA, F. R. Quem mandou nascer mulher? Estudos sobre crianças e adolescentes no Brasil. Rio de Janeiro: Record; Rosa dos Tempos, 1997.

MANNONI, M. Educação impossível. Lisboa: Moraes, 1976.

MARTINS, J., BICUDO, M. A.V. A Pesquisa qualitativa em psicologia: fundamentos e recursos básicos. São Paulo: Moraes, 1989.

MINAYO, M. C. de S. O Desafio do conhecimento: pesquisa qualitativa em saúde. São Paulo: Hucitec, 1992.

NICOLACl-da-COSTA, A. M. Sujeito e cotidiano: um estudo da dimensão psicológica do social. Rio de Janeiro: Campus, 1987.

NOVAES, M. E. Professora primária: mestra ou tia. São Paulo: Cortez, 1984.

RIBEIRO, S. da C. A Educação e a inserção do Brasil na modernidade. Cadernos de Pesquisa, São Paulo, n.84, p.63-82, fev. 1993.

ROSEMBERG, F. Educação Formal e mulher: um balanço parcial da bibliografia. In: OLIVEIRA, A., BRUSCHINI, C. Uma questão de gênero. Rio de Janeiro: Rosa dos Tempos, 1992. p. $|5|-82$.

ROSEMBERG, F., AMADO, T. Mulheres na escola. Cadernos de Pesquisa, São Paulo, n.80, p. 62-74, fev. 1992.

ROSENTHAL, R., JACOBSON, L. Profecias auto-realizadoras em sala de aula: as expectativas dos professores como determinantes não intencionais da competência intelectual. In: PATTO, M. H. Introdução à psicologia escolar. São Paulo: Queiroz, I 981 . p.258-95. 
SÁ, C.P. Representações sociais: o conceito e o estado atual da teoria. In: SPINK, M. J. O Conhecimento no cotidiano. São Paulo: Brasiliense, 1993. p. $19-45$.

SADKER, M. Failing at fairness: how our schools cheat girls. New York: Touchstone, 1995.

SCOTT, J. W. Prefácio a gender and politics of history. Cadernos Pagu, Campinas, n.3, p. I I27, 1994.

SEARS, R., MAcCOBY, E., LEVIN, H. Patterns of child rearing. New York: Harper and Row, 1957.

SILVA, C. D. et al. A Exclusão escamoteada: reprovação das crianças negras. Cadernos de Educação FaE/UFPel. Pelotas, n.7, p.47-59, 1996.

SPITZ, R. A. Desenvolvimento emocional do recém-nascido. São Paulo: Pioneira, 1960.

THIOLLENT, M. Crítica metodológica, investigação social e enquete operária. São Paulo: Polis, 1982.

VICTORA, C., BARROS, F., VAUGHAN, P. Epidemiologia da desigualdade. São Paulo: Hucitec, 1988.

WALKERDINE, V. O Raciocínio em tempos pós-modernos. Educação \& Realidade, FacEd/ 
